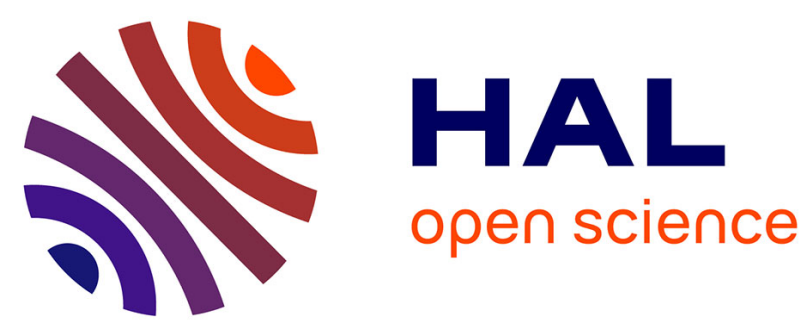

\title{
Cardiovascular changes induced by cold water immersion during hyperbaric hyperoxic exposure.
}

Alain Boussuges, Florence Molenat, Aliocha Grandfond, Jacques Regnard, Jean-Pierre Wolf, François Galland, Claude Robinet

\section{- To cite this version:}

Alain Boussuges, Florence Molenat, Aliocha Grandfond, Jacques Regnard, Jean-Pierre Wolf, et al.. Cardiovascular changes induced by cold water immersion during hyperbaric hyperoxic exposure.. Clinical Physiology and Functional Imaging, 2007, 27 (5), pp.268-74. 10.1111/j.1475-097X.2007.00747.x . ssa-00194919

\section{HAL Id: ssa-00194919 \\ https://hal-ssa.archives-ouvertes.fr/ssa-00194919}

Submitted on 7 Dec 2007

HAL is a multi-disciplinary open access archive for the deposit and dissemination of scientific research documents, whether they are published or not. The documents may come from teaching and research institutions in France or abroad, or from public or private research centers.
L'archive ouverte pluridisciplinaire HAL, est destinée au dépôt et à la diffusion de documents scientifiques de niveau recherche, publiés ou non, émanant des établissements d'enseignement et de recherche français ou étrangers, des laboratoires publics ou privés. 
Original article

\title{
CARDIO-VASCULAR CHANGES INDUCED BY COLD WATER IMMERSION DURING HYPERBARIC HYPEROXIC EXPOSURE
}

Running Head : Hyperbaric hyperoxia and cold water immersion

\author{
Authors : \\ Alain BOUSSUGES 1,2, MD. PhD, Florence MOLENAT 2,3, MD PhD, Aliocha \\ GRANDFOND 2, MD, Jacques REGNARD 4, Jean-Pierre WOLF 4, François \\ GALLAND 1, MD, Claude ROBINET 1,2, MD. \\ 1 - Institut de Médecine Navale du Service de Santé des Armées, Boulevard de Saint- \\ Anne, Toulon-France \\ 2 - Laboratoire de Recherche EA 3280, “Physiopathologie et action thérapeutique des \\ gaz sous pression", Faculté de Médecine Nord, Marseille- FRANCE \\ 3 - Service de Réanimation médico-chirurgicale et de surveillance continue, Centre \\ Hospitalier du pays d'Aix, Aix en Provence-FRANCE \\ 4 - Université de Franche Comté, EA 3920, IFR133, Physiologie, Faculté de Médecine \\ et Centre Hospitalier Universitaire, Explorations Fonctionnelles, Besançon, France
}

Corresponding author :

\section{Docteur Alain Boussuges}

IMNSSA BP 610, 83800 Toulon Armées, France

Tel : (0033) 442335024

Fax : (0033) 442339132

alainboussuges@libertysurf.fr

a.boussuges@imnssa.net 


\section{Abstract:}

The present study was designed to assess the cardiac changes induced by cold water immersion compared with dry conditions during a prolonged hyperbaric and hyperoxic exposure (ambient pressure between 1.6 to 3 ATA and PiO2 between 1.2 to 2.8 ATA).

Ten healthy volunteers were studied during a 6 hours compression in a hyperbaric chamber with immersion up to the neck in cold water while wearing wet suits. Results were compared with measurements obtained in dry conditions. Echocardiography and Doppler examinations were performed after 15 minutes and 5 hours. Stroke volume, left atrial and left ventricular (LV) diameters remained unchanged during immersion whereas they significantly fell during the dry session. As an index of LV contractility, Percent Fractional shortening remained unchanged, in contrast with a decrease during dry experiment. Heart rate significantly decreased after 5 hours, although it had not changed during the dry session. The changes in the total arterial compliance were similar during the immersed and dry sessions, with a significant decrease after 5 hours. In immersed and dry conditions, cardiac output was unchanged after 15 minutes but decreased by almost $20 \%$ after 5 hours. This decrease was related to a decrease in heart rate during immersion and to a decrease in stroke volume in dry conditions.

The hydrostatic pressure exerted by water immersion on the systemic vessels could explain these differences. Indeed, the redistribution of blood volume toward the compliant thoracic bed may conceal a part of hypovolemia that developed in the course of the session.

\section{8 words}

Keys words : Diving, hyperbaric hyperoxia, cardiac function, cold exposure, healthy volunteers, echocardiography-Doppler 


\section{INTRODUCTION}

The diving-induced changes in hemodynamics have been mostly studied during experiments conducted in hyperbaric chambers. When the ambient pressure is increased, the elevated oxygen partial pressure (hyperoxia) leads to bradycardia, decreases cardiac output and triggers an increase in systemic vascular resistance (Whalen et al., 1965; Hahnloser et al., 1966; Shida \& Lin 1981; Pelaia et $a l .$, 1992; Lund et $a l ., 1999$; Rossi \& Boussuges, 2005). A negative inotropic effect of hyperoxia has been reported during exposure to normobaric conditions (Berk et al., 1983; Lodato, 1989), but was not found during exposure to hyperbaric hyperoxia as the increased ambient pressure causes an elevation in cardiac contractility (Savitt et al., 1994; Risberg et al., 1995). We previously reported our observations on hemodynamic changes in healthy subjects during prolonged hyperbaric hyperoxic exposure while breathing through SCUBA, fasting and with intermittent exercise (Molenat et al., 2004). During open sea diving, in addition to hyperoxia and increased ambient pressure, the subjects face environmental constraints such as immersion and cold exposure. These environmental features are also known to be responsible for hemodynamic changes (Lin, 1984). We hypothesised that the supplemental constraints induced by cold water immersion modify the hemodynamic profile usually observed during experiments conducted in hyperbaric chambers. Therefore, the present study was designed to assess the circulatory and cardiac changes induced by cold water immersion compared with dry conditions during a prolonged hyperbaric and hyperoxic exposure (HH). Ten subjects underwent two similar $6 \mathrm{HH}$ exposures performing a dry session (Dry $\mathrm{HH}$ ), and after 4 weeks, a wet session with immersion up to the neck (sternoclavicular notch) in cold water (immersed HH) while wearing wet suits. The hemodynamic modifications during immersion were studied using trans-thoracic pulsed Doppler echocardiography with the probe in a wet suit muff. Results were compared with measurements obtained in dry conditions. 


\section{MATERIAL AND METHODS}

\section{Experimental protocol}

The experimental procedure was designed to insure the conditions of a real dive as near as possible, combining $\mathrm{HH}$, SCUBA breathing and exercise, without any opportunity to drink or eat during the session. The hyperbaric chamber consisted of a large cylindrical chamber (diameter $2 \mathrm{~m}$, length $4 \mathrm{~m}$ ), where the humidity was maintained between 50 and $80 \%$ and the temperature between 20 and $24{ }^{\circ} \mathrm{C}$.

Ten trained military divers aged $32+/-5$ years $(26-40$ years), weight (82 +/- $11 \mathrm{kgs}(61-104 \mathrm{kgs})$ and height $181+/-9 \mathrm{~cm}(168-193 \mathrm{~cm})$ took part in the experiment. All subjects had a negative history of hypertension and cardiovascular or kidney diseases, and none was taking any medication at the time of the study. The local Ethics Committee approved the protocol, and written informed consent was obtained after careful oral and written explanation of the experiment. Criteria for the experiment to be stopped were the request of the subject or the appearance of convulsions or any preliminary sign of seizure.

All subjects underwent two similar 6-h exposures with 1-month intervals, the first one in dry conditions and the second immersed up to the neck, in cold water. During the dry experiments, divers wore cotton short and tee-shirt. During the immersed session, the average water temperature was $14.4^{\circ} \mathrm{C}\left(\min 13.6^{\circ} \mathrm{C}-\max : 15.9^{\circ} \mathrm{C}\right)$. Divers wore a polar fiber underwear, a $2 \mathrm{~mm}$ neoprene farmer wet suit and a $7 \mathrm{~mm}$ Neoprene farmer and jacket wet suit (total of $16 \mathrm{~mm}$ neoprene on the thorax), individually fitted by a local manufacturer (Squale - Toulon France).

The volunteers spent the two experimental sessions (dry and immersed) in the same sitting position. The subjects sat in a tank containing a submersible mechanical 
cycle ergometer designed for the study. Rectal temperature was continuously monitored. Subjects were also required to report any cold sensation or shivering.

In both conditions, subjects were breathing using a closed-circuit SCUBA (Oxymixgers 97, Aqualung, Carros, France) positioned on their backs. The breathing gas was $100 \%$ oxygen or an inspired gas enriched with oxygen $(60 \%$ oxygen $/ 40 \%$ nitrogen).

The French Navy has previously measured the supplemental work and the inspiratory and expiratory pressures induced at $\mathbf{1 0}$-meter depth by the breathing apparatus, positioned on the back with subjects in a sitting position (Figure 1). A supplemental work amounting at 0.5 Joule per liter of ventilation has been measured and the pressure was found negative $(-4 \mathrm{~cm} \mathrm{H20})$ at the inspiratory time, and positive $(+5 \mathrm{~cm} \mathrm{H2O})$ at the expiratory time.

The continuous monitoring of the ambient pressure and of the $\mathrm{FiO} 2$ in the inspiratory circuit allowed a continuous monitoring of the $\mathrm{PiO} 2$.

All subjects were exposed for 6 hours to the same compression profile, with pressure varying between 1.6 to 2 ATA $(1$ ATA $=101.325 \mathrm{kPa})$ with some short descent to 2.8 ATA. Divers were exposed to a PiO2 of 1.2 ATA during 180 minutes (min), a PiO2 between 1.2 and 1.6 ATA during $150 \mathrm{~min}$, a PiO2 above 1.6 ATA with some peak up to 2 ATA, during 20min and a PiO2 under 1 ATA during 10min. Each experimental exposure comprised the same pattern of alternating periods of rest and exercise (two cycling periods for a total duration of 165 minutes).

Before and after each exposure, venous blood samples from an antecubital vein, electrocardiographic (ECG) data, and measurements of SAP and DAP were taken after $20 \mathrm{~min}$ of rest in a quiet room at $24^{\circ} \mathrm{C}$. Moreover, the subjects were weighed on a precision scale (Ohaus, Pine Brook, NJ, USA) 


\section{Echographic and Doppler study}

\section{Technical considerations}

The echocardiography-Doppler examinations were performed using a Diasonics Vingmed CFM 750 type ultrasonography machine (GE Ultrasound, Millwaukee, USA).

The same measurements were performed on a control day at normobaric pressure and during the two experimental sessions, the first in dry condition and the second during head out water immersion. The ultrasonography unit was located outside the hyperbaric chamber and connected to a combined 3.25 MHz imaging/2.5 MHz Doppler probe inside the chamber via a feed-through into the hull. This technique did not expose the ultrasonographic unit to pressure changes. The explorations were carried out by an investigator ( $\mathrm{AB}$ or $\mathrm{AG})$ compressed to the pressure of the subjects within the chamber. The probe was brought up to the thorax through a wet suit muff.

Subjects were in a sitting position with a slight left lateral shift, on a seat located below a porthole. The inside investigator attempted echocardiography Doppler examination with visual control on the outside monitor through the porthole. Also, a second investigator (FM, AG) stayed outside the hyperbaric chamber and positioned the monitor in such a way that the inside investigator could see it. The two investigators communicated via a microphone. The investigator outside the chamber processed the recording of the echocardiogram using the Diasonics Vingmed computer system, and also recorded the examinations on VHS videotapes, to be reviewed and analysed later. The mean duration for each test was about 30 minutes.

Schedule of the echographic examination:

A reference examination, at sea level, was performed 4 to 5 days before the first experimental session. At this time, any cardiac abnormalities led to the exclusion of the 
subject from the study. At the time of the compression, the schedule of the experiment permitted 2 echographic examinations as follows: an early examination after 15 minutes of compression and a late examination after 5 hours of compression, before the last exercise period. In both cases, the ambient pressure and $\mathrm{PiO} 2$ were identical, i.e. respectively 2 ATA and 1.2 ATA. 2D echocardiographic images were obtained from a transthoracic approach. Examinations were made using two dimensional and $\mathrm{M}$ mode echocardiography associated with pulsed and continuous wave Doppler. Each view was recorded for 30 seconds on videotape. Doppler recordings were performed at the end of a normal expiration to eliminate the effects of the respiration on the parameters studied. Measurements were averaged from at least three different beats. Tape recordings were obtained at a speed of $100 \mathrm{~mm} / \mathrm{s}$ with simultaneous tracing of the electrocardiogram. Sphygmomanometric blood pressure measurements on the right arm were obtained before each examination. Mean arterial blood pressure (MAP) was calculated as : MAP $=\mathrm{DAP}+1 / 3(\mathrm{SAP}-\mathrm{DAP})$, where SAP and DAP were respectively the systolic and diastolic arterial blood pressure. Pulse pressure was defined as systolic minus diastolic blood pressure : PP = SAP - DAP

Echographic parameters: We combined M-mode and 2D echocardiography with continuous and pulsed Doppler.

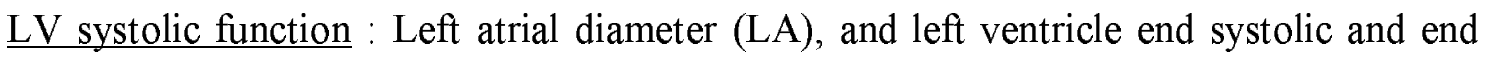
diastolic diameters (LVEDD, LVESD) were measured by M-mode echocardiography from the left parasternal short and long axis views. The standard index of global LV systolic performance was LV percent fractional shortening (\%FS). \%FS was taken as the ratio (LVEDD - LVESD/ LVEDD) Heart rate (HR) was recorded by echocardiogram and the rate was averaged over $60 \mathrm{~s}$. Cardiac output $(\mathrm{CO})$ was derived from the aortic flow. Aortic cross section area (ACSA) was first measured by 2D echocardiography from the left parasternal long axis view at the level of the aortic root. The aortic systolic 
flow velocity time integral (AoVTI) was measured by computer assisted determination from the pulsed-wave Doppler profile of the aortic blood flow from the apical four chamber view, allowing the calculation of stroke volume (SV = AoVTI x ACSA) and $\mathrm{CO}(\mathrm{CO}=\mathrm{SV} \times \mathrm{HR})$


independent of the LV preload. LVmWS is a function of the inner pressure of the LV at the end of the systole (considered as equal to the systolic blood pressure (SBP) in the absence of any aortic shrinking or mitral insufficiency) and of the myocardial contractility. It was calculated as follows: LVmWS $=(0.33 \mathrm{SAP} \times \mathrm{LVESD}) / \mathrm{LVESPW}$ $(1+$ LVESPW /LVESD).

The total arterial compliance was calculated as SV/PP (Chemla et al.,1998), where PP was the pulse pressure.

Left Ventricular filling: Transmitral blood flow velocities were obtained from the apical four chamber view, positioning the sample volume at the mitral valve leaflet tips. Doppler velocity curves were recorded at $100 \mathrm{~mm} / \mathrm{s}$. Peak velocity and velocity time integral (VTI) of the initial flow (E wave), representing the early filling phase, and of the late flow (A wave), representing the atrial contraction, were measured. The peak velocity ratio (E/A) and the ratio of the A wave VTI to the total VTI (relative contribution of atrial contraction to the total LV filling) were calculated. In addition, two other variables were measured: the deceleration pressure half time of early diastolic transmitral flow (PHT) and the isovolumetric relaxation time (IVRT). The IVRT was the interval from the aortic valve closure signal to the mitral valve opening signal.

\section{Statistical Analysis}

Data are expressed as mean +/- SEM. Statistical tests were run on the Sigma Stat software. The cohorts for comparison consisted of the ten subjects at 3 time points: 
reference, after 15 minutes of exposure to immersed $\mathrm{HH}$ and after 5 hours of exposure to immersed $\mathrm{HH}$. The data distribution was analysed with a Kolmogorov -Smirnov test. Comparison between cohorts of continuous variables having a normal distribution was carried out with analysis of variance with repeated measures ANOVA; the post-hoc comparison of dichotomous variables was performed with a Tukey's test. In the case of variable cohorts not having a normal distribution, comparisons were performed with non-parametric univariate analysis (Friedmann's test) and the post-hoc dichotomous comparisons with a Dunn's test. Differences between groups were considered significant at $\mathrm{p}<0.05$

We also compared the values obtained at 15 min and 5 hours of immersed $\mathrm{HH}$ groups in the present study to values obtained at $15 \mathrm{~min}$ and 5 hours during dry $\mathrm{HH}$ exposure in the same subjects with the same measurements. When the data were normally distributed, a Student's test for paired data was used. If the distribution was not normal, the Wilcoxon's paired signed rank test was used. 
RESULTS

Similar weight loss was induced by the two sessions (Table 1): $-2.2+/-0.4 \mathrm{~kg}$ after dry $\mathrm{HH}$ and $-2.4+/-0.6 \mathrm{~kg}$ after immersed $\mathrm{HH}$. Furthermore, no significant changes in SAP and DAP were observed after the two exposures.

Immersed $\mathrm{HH}$

Divers performed immersed $\mathrm{HH}$ exposure without any incident. All the divers complained from cold at the end of the two rest periods. Shivering occurred after 100min of exposure in 8 divers, and ceased at the time of the first exercise period in all subjects. Four of them shivered again after 5 hours of exposure before the second exercise period. Figure 2 displays the mean rectal temperature (Tre) recorded during the immersed sessions. A significant decrease of Tre was observed after $70 \mathrm{~min}$. Tre had significantly increased 60 minutes after the beginning of the exercise, and remained increased until 40 minutes after the end of exercise. A second significant decrease of Tre occurred after 5 and half hours of exposure and disappeared after the second bout of exercise.

\section{Hemodynamic and echocardiographic measurements during immersed HH (Table}

\section{2 and 3)}

Systolic arterial pressure (SAP), Mean AP and Diastolic AP remained unchanged during the whole exposure. Pulse pressure increased significantly after 5 hours of immersed HH. HR had not changed significantly after 15 minutes but was significantly decreased 
after 5 hours. Stroke volume remained unchanged. In total, CO was unchanged after 15 minutes but was decreased by almost $20 \%$ after 5 hours $(p=0.02)$.

LA diameter, LVEDD and LVESD did not show any change. The \% FS and the LVmWS remained unchanged. The total arterial compliance was unchanged after 15 minutes but decreased significantly after 5 hours $(\mathrm{p}=0.017)$. There was no significant modification of the transmitral flow profiles and of the IVRT after 15 minutes and 5 hours of exposure of immersed HH (table 4)

Hemodynamic and Echocardiographic studies: Comparisons with the dry session (table 2 and 3)

LA diameters were significantly higher during immersed $\mathrm{HH}$ than during dry $\mathrm{HH}$. LVEDD was significantly higher during immersed than dry $\mathrm{HH}$ after 15 minutes but was not significantly different after 5 hours.

As LV systolic indices, \%FS was significantly greater after 15 minutes exposure in the immersed $\mathrm{HH}$ than during dry $\mathrm{HH}$ but was similar in the two sessions after 5 hours exposure. Stroke volume was not different after 15 minutes in the immersed and dry sessions. After 5 hours there was a trend for a higher stroke volume when immersed than in the dry condition $(91+/-14$ versus $78+/-14 \mathrm{ml}-\mathrm{p}=0.09)$.

Heart rate was not different after 15 minutes in immersed and dry $\mathrm{HH}$ but was significantly lower after 5 hours immersion.

Cardiac output was similar in immersed and dry conditions, both after 15 minutes and after 5 hours.

The LV afterload indicator, LV meridional wall stress (LVmWS) was unchanged during the whole immersed $\mathrm{HH}$ exposure at variance with a significant increase during dry exposure. 
Pulse pressure after 5 hours was significantly higher during immersed than dry $\mathrm{HH}$. Systolic, mean and diastolic arterial pressures were not different in the immersed and dry sessions.

The changes in the total arterial compliance were similar during the immersed and dry sessions, with values not different from the reference measurement after 15 minutes, but significantly lower after 5 hours. 


\section{DISCUSSION}

This work is the first with measurement of hemodynamic parameters during prolonged exposure to both cold water immersion and hyperbaric hyperoxia. We performed an Echocardiography, and Doppler study with a method previously used during experiments in hypobaric or hyperbaric conditions with satisfactory results, (Lafay et $a l .$, 1997; Boussuges et $a l .$, 2000). In the present study, we report cardiovascular changes during 6 hours of immersed HH. In addition, these results were compared with the observations made in the same subjects during a similar profile of hyperbaric hyperoxia in a dry condition.

\section{5 minutes}

In contrast with the dry experiment, after 15 minutes of hyperbaric exposure in cold water immersion LA diameter, $\mathbf{L V}$ dimensions and stroke volume were unchanged as compared with the reference determination. This evidenced a lack of decrease in LV preload in immersed condition. This may be caused by the water hydrostatic pressure (Lin, 1984). Indeed, the restriction of the systemic vascular capacity triggers a redistribution of some peripheral blood volume into the intrathoracic vascular network, and favours venous return to the heart. Furthermore, the increased hydrostatic pressure applied on the skin triggers an increase in plasma volume via a shift of interstitial fluid through the capillary walls in the portion of the body submerged in water. Transcapillary fluid shift occurs during the first minutes of exposure and leads to an increase in plasma volume and some hemodilution (Greenleaf et $a l$., 1981; Miki et $a l$, 1989; Johanssen et $a l . ; 1998)$. Finally, all studies observe an increase in central blood volume associated with an increase in cardiac diameters and stroke volume during head out water 
immersion (Arborelius et al., 1972; Lin, 1984; Christie et al., 1990; Sramek et al., 2000).

In our study, divers were breathing through a SCUBA, leading to increased intrathoracic and intrapleural pressures. In dry conditions, these mechanical breathing strains caused a decrease in LV preload (Molenat et al., 2004). In the present report, the unchanged cardiac dimensions and stroke volume could result from two opposing effects: water immersion which increased central blood volume and ventilation strains of the SCUBA which acted to decrease cardiac preload.

The $\% \mathrm{FS}$ was not changed during immersed $\mathrm{HH}$ exposure, suggesting that the LV contractility did not vary either. Conversely, in dry conditions, an almost $10 \%$ reduction of $\% \mathrm{FS}$ was found. This echocardiographic index is dependent on contractility and both preload and afterload. Since Starling's work, it has been well known that increasing the initial length of the muscle fiber by increasing the heart volume enhances the cardiac contractility. Consequently, in dry condition, the decrease in LV preload led to a reduction in $\% \mathrm{FS}$, whereas during water immersion, $\mathrm{LV}$ preload was unchanged leading to the stability in $\% \mathrm{FS}$.

The systolic, mean and diastolic blood pressure, total arterial compliance and LVmWS were unchanged after 15 minutes of hyperbaric exposure in water immersion. In contrast, under dry conditions, LVmWS increased suggesting an elevation in LV afterload that we attributed to a decrease in cardiac contractility and/or to an arterial vaso-constriction induced by hyperoxia. In thermoneutral water immersion past studies have shown a decrease in systemic vascular resistance and an increase in arterial compliance (Arborelius et al., 1972; Farhi \& Linnarsson, 1977; Park et al., 1999; Boussuges, 2006). Consequently, modifications of the systemic arterial circulation induced by immersion could explain that the afterload indices did not increase after 15 min of immersed $\mathrm{HH}$ exposure before any adverse effect of cold exposition. Indeed, the 
wet suits worn by the subjects are designed for real diving operation and within $15 \mathrm{~min}$ rest, their insulating capacity had not been overcome.

At least, echocardiography-Doppler permitted, in our subjects, the assessment of LV filling. In normal young adults, LV elastic recoil is vigorous and myocardial relaxation is swift, so that most LV filling is completed during the early diastole with only a small contribution of filling during atrial contraction. This results in an elevated transmitral E velocity peak, a smaller transmitral A velocity peak and a E/A ratio greater than 1 (Oh et $a l$., 1997), as we observed in our subjects at the sea level point during baseline measures. After 15 minutes, LV filling pattern seemed unchanged. However, this should be analysed in the light of the above results. Indeed, the major determinant of the transmitral flow is the pressure gradient between LA and LV (Oh et $a l$., 1997), depending on LV preload, relaxation and contractility. In our subjects, the decrease in LV preload due to the breathing apparatus should have led to a decreased peak $\mathrm{E}$ velocity, an increased peak $\mathrm{A}$ velocity and a decreased E/A ratio. However, water immersion, by increasing the LA pressure and LA/LV gradient might have increased the early LV filling and the E/A ratio (Appleton \& Hatle, 1992). As a result of those two opposing effects, the LV filling pattern appeared unchanged.

\section{5 hours}

During the hyperbaric exposure, divers did not drink or eat. They performed two periods of exercise. In dry conditions, hypovolemia after 5 hours was evidenced by the decrease in stroke volume and in cardiac diameters decrease (Molenat et al., 2004). In contrast with the dry experiment, left ventricular diameters and stroke volume were not reduced after 5 hours of hyperbaric exposure with water immersion. Again, the hydrostatic pressure exerted by immersion provides a likely explanation to this paradox. 
Indeed, during immersion, the redistribution of blood volume toward the compliant thoracic bed may conceal a part of hypovolemia (Christie et al., 1990; Norsk et al., 1990; Sramek et $a l ., 2000$ ). Furthermore, as immersion persists, up to 12 hours, the shift of fluid from the interstitial and cellular compartment to the plasma persists (Johansen et $a l ., 1992)$, and explains the lower reduction in plasma volume during the immersed $\mathrm{HH}$ in comparison with dry condition. For this reason, the left ventricular filling profile was also unchanged.

Bradycardia was observed after 5 hours of hyperbaric exposure. Bradycardia could be explained by two factors. In contrast with dry session, hyperoxia-induced bradycardia was not masked by a hypovolemia-induced tachycardia. In addition, the divers progressively experienced the sensation of cold during the resting periods and some went to shivering. Thermal monitoring evidenced a continuous decrease of rectal temperature during these periods. Consequently, at the time of our second echocardiographic examination, cold exposure might have contributed to the heart rate lowering (Sramek et $a l ., 2000$ ). As the result of the unchanged stroke volume and of the lowered heart rate, cardiac output decreased to a similar degree as in dry condition.

An increase in pulse pressure and a decrease in total arterial compliance were observed after 5 hours of immersed $\mathrm{HH}$ exposure, suggesting arterial vasoconstriction. These modifications could be attributed both to hyperoxia and to a reaction to peripheral cooling. A similar reduction in total arterial compliance was observed after 5 hours of dry $\mathrm{HH}$ exposure but the mechanisms might have been different. In the dry condition, vasoconstriction might have been triggered by both hyperoxia and hypovolemia.

In contrast with the decrease in total arterial compliance, LVmWS was unchanged after 5 hours of immersed $\mathrm{HH}$ exposure. This index is a function of the systolic blood pressure and of the LV dimensions, both of them being unchanged during hyperbaric exposure with water immersion. 
In conclusion, hemodynamic changes induced by exposure to the same profile of hyperbaric hyperoxia were quite different in cold water immersion and in dry condition. The relative hypervolemia caused by water immersion concealed the loss of plasma volume, which occurred during the six hours of cold water immersion with SCUBA breathing and intermittent exercise. The stroke volume assessed non-invasively with a thoracic impedance device by another team during the same experiment, demonstrated a greater decrease post immersion $\mathrm{HH}$ compared to the SV changes after the dry condition (Mourot et al., 2004). This modification was supported by the changes in plasma volume observed at the same time after immersion. While the unchanged indices of cardiac function, and arterial pressure appeared to evidence a maintained efficient plasmatic volume during immersion, the loss of fluids may be as great as or greater, than in a dry environment. Finally, the adverse circulatory effects of a prolonged stay in water are unveiled only after emersion. 
Acknowledgement: The authors gratefully acknowledge the ten volunteers and the medical and technical board of the CEPHISMER centre, Toulon, France. This study was supported by a research DGA grant (PEA n 9808 09). 


\section{References}

1. Appleton CP, Hatle LK. The natural history of left ventricular filing abnormalities, assessment by two dimensional and Doppler echocardiography. Echocardiography. (1992); 9: 437-457.

2. Arborelius M jr, Balldin UI, Lilja B, Lundgren CEG. Hemodynamic changes in man during immersion with the head above water. Aerosp Med (1972); 43: 592-598.

3. Berk J, Hagen J, Levy M. The cardiovascular action of oxygen breathing, Effect on adrenergic stimulation. Eur Surg Res (1983); 15: 185-192.

4. Boussuges A, Molénat F, Burnet H, Cauchy E, Sainty JM, Jammes Y, Richalet JP. Operation EVEREST III (Comex'97), Modifications of cardiac function secondary to altitude-induced hypoxia, An echocardiographic-Doppler study. Am J Respir Crit Care Med (2000); 161: 264-267.

5. Boussuges A. Immersion in thermoneutral water: Effects on arterial compliance. Aviat Space Environ Med (2006); 77: 1183-7

6. Chemla D, Hébert JL, Coirault C, Zamani K, Suard I, Colin P, Lecarpentier Y. Total arterial compliance estimated by stroke volume to aortic pulse pressure ratio in humans. Am J Physiol (1998); 274 (Heart Circ Physiol 43): H500-H505.

7. Christie JL, Sheldahl LM, Tristani FE, Wann LS, Sagar KB, Levandoski SG, Ptacin MJ, Sobocinski KA, Morris RD. Cardiovascular regulation during head-out water immersion exercise. J Appl Physiol (1990); 69: 657-664.

8. Farhi LE, Linnarsson D. Cardiopulmonary readjustments during graded immersion in water at 35 C. Respir Physiol (1977); 30: 35-50.

9. Greenleaf JE, Shvartz E, Keil LC Hemodilution, Vasopressin suppression, and diuresis during water immersion in man. Aviat Space Environ Med (1981); 52: 329336. 
10. Hahnloser P.B, Domanig E, Lamphier E, Schlenk WG. Hyperbaric oxygenation, Alterations in cardiac output and regional blood flow. $J$ Thoracic Cardiovascular Surg (1966); 2: 223-230.

11. Johansen LB, Foldager C, Stadeager C, Kristensen MS, Bie P, Warberg J, Kamegai M, Nork P. Plasma volume, fluid shifts, and renal responses in humans during $12 \mathrm{~h}$ head-out water immersion. J Appl Physiol (1992); 83: 695-699.

12. Johansen LB, Pump B, Warberg J, Christensen NJ, Norsk P. Preventing hemodilution abolishes natriuresis of water immersion in humans. Am J Physiol (1998); 275(3 Pt 2): R879-888.

13. Lafay V, Boussuges A, Ambrosi A, Barthelemy P, Frances Y, Gardette B, Jammes Y. Doppler-Echocardiographic study of cardiac function during a 36 atm $(3.650$ kPa) human dive. Undersea Hyperbaric Med (1997); 24: 67-71.

14. Lin YC. Circulatory functions during immersion and breath-hold dives in humans. Undersea Biomed Res (1984); 11: 123-138 .

15. Lodato RF. Decreased O2 consumption and cardiac output during normobric hyperoxia in conscious dogs. J Appl Physiol (1989); 67: 1551-1559.

16. Lund VE, Kentala E, Scheinin H, Klossner J, Helenius H, Sariola-Heinonen K, Jalonen J. Heart rate variability in healthy volunteers during normobaric and hyperbaric hyperoxia. Acta Physiol Scand (1999); 167: 29-35.

17. Miki K, Klocke MR, Hong SK, Krasney JA. Interstitial and intravascular pressures in conscious dogs during head-out water immersion. Am J Physiol (1989); 257: R35864.

18. Molenat F, Boussuges A, Grandfond A, Rostain JC, Sainty JM, Robinet C, Galland F, Meliet JL. Hemodynamic effects of hyperbaric hyperoxia in healthy volunteers: An Echocardiographic and Doppler study. Clin Science (2004); 106: 389-395. 
19. Mourot L, Wolf JP, Galland F, Robinet C, Courtière A, Bouhaddi M, Meliet JL, Regnard J. Short-term vasomotor adjustments to post immersion dehydration are hindred by natriuretic peptides. Undersea Hyperbaric Med (2004); 31:147-154.

20. Norsk P, Bonde-Petersen F, Christensen NJ. Catecholamines, circulation, and the kidney during water immersion in humans. J Appl Physiol (1990); 69: 479-484

21. Oh JK, Appleton CP, Hatle LK, Nishimura RA, Seward JB, and Tajik AJ. The noninvasive assement of left ventricular diastolic function with two-dimensional and Doppler echocardiography. J Am Soc Echocardiogr (1997); 10: 246-270.

22. Park KS, Choi JK, Park YS. Cardiovascular regulation during water immersion. Appl Human Sci (1999); 18: 233-241.

23. Pelaia P, Rocco M, Conti G. Haemodynamic changes during hyperbaric oxygen therapy. J Hyperbaric Med (1992); 7: 229-237.

24. Risberg J, Skei S, Tyssebotn I. Effects of gas density and ambient pressure on myocardial contractility in the rat. Aviat Space Environ Med (1995); 66: 1159-1168.

25. Rossi P, Boussuges A. Hyperoxia-induced arterial compliance decrease in healthy man. Clin Physiol Funct Imaging (2005); 25: 10-15.

26. Savitt M.A, Rankin J.S, Elberry J.R, Owen C.H, Camporesi E.M. Influence of hyperbaric oxygen on left ventricular contractility, total coronary blood flow, and myocardial oxygen consumption in the conscious dog. Undersea Hyperbaric Med (1994); 21: 169-183.

27. Shida KK, Lin YC. Contribution of environmental factors in development of hyperbaric bradycardia. J Appl Physiol (1981); 50: 731-735.

28. Sramek P, Simeckova M, Jansky L, Savlikova J, Vybiral S. Human physiological responses to immersion into water of different temperatures. Eur J Appl Physiol (2000); 81: 436-442. 
29. Whalen RE, Saltzman HA, Halloway DH, Mcintosh HD, Sieker HO, Brown IW.

Cardiovascular and blood gas responses to hyperbaric oxygenation. Am J Cardiol (1965); 15: 638-646. 
Table 1 : Weight and arterial pressure recorded before and after dry and immersed hyperbaric hyperoxia exposures

\begin{tabular}{lcccc}
\hline & \multicolumn{2}{c}{ Dry Hyperbaric Hyperoxia } & \multicolumn{2}{c}{ Immersed Hyperbaric Hyperoxia } \\
& Before & After & Before & After \\
\hline & & & & \\
Weight $(\mathrm{kg})$ & $81.7+/-11$ & $79.4+/-11 *$ & $80.6+/-12$ & $78.2+/-11 *$ \\
SAP $(\mathrm{mmHg})$ & $120+/-8$ & $126+/-12$ & $117+/-7$ & $122+/-8$ \\
DAP $(\mathrm{mmHg})$ & $75+/-11$ & $70+/-10$ & $71+/-9$ & $73+/-9$ \\
& & & & \\
\hline
\end{tabular}


Table 2 : Hemodynamic datas recorded during the two sessions

\begin{tabular}{|c|c|c|c|c|c|}
\hline & \multirow[t]{2}{*}{ Sea level } & \multicolumn{2}{|c|}{ Dry Hyperbaric Hyperoxia } & \multicolumn{2}{|c|}{ Immersed Hyperbaric Hyperoxia } \\
\hline & & 15 minutes & 5 hours & 15 minutes & 5 hours \\
\hline HR (beat per min) & $62+/-7$ & $69+/-12$ & $63+/-11$ & $66+/-9$ & $54+/-9 * \S^{£}$ \\
\hline $\mathrm{CO}(1 / \mathrm{min})$ & $6.1+/-1.1$ & $6.3+/-0.9$ & $4.9+/-0.7 * \S$ & $6.3+/-0.9$ & $4.8+/-0.6 * \S$ \\
\hline $\mathrm{SV}(\mathrm{ml})$ & $98+/-15$ & $93+/-20 *$ & $78+/-14 * \S$ & $98+/-15$ & $91+/-14$ \\
\hline Mean BP (mmHg) & $91+/-7$ & $93+/-13$ & $93+/-9$ & $92+/-11$ & $91+/-10$ \\
\hline Systolic BP (mmHg) & $124+/-9$ & $131+/-15$ & $130+/-9$ & $128+/-18$ & $132+/-9$ \\
\hline Diastolic BP (mmHg) & $74+/-8$ & $74+/-15$ & $75+/-10$ & $74+/-10$ & $71+/-13$ \\
\hline Pulse Pressure $(\mathrm{mmHg})$ & $50+/ 10$ & $58+/-19$ & $55+/-7$ & $55+/-15$ & $60+/ 11 * \S^{£}$ \\
\hline
\end{tabular}

${ }^{*} \mathrm{p}<0.05$ versus reference, $\S \mathrm{p}<0.05$ versus 15 min of the same environment, ${ }^{£} \mathrm{p}<0.05$ versus dry at the same time point 
Table 3 : Echocardiographic variables recorded during the two sessions

\begin{tabular}{|c|c|c|c|c|c|}
\hline & \multirow[t]{2}{*}{ Sea level } & \multicolumn{2}{|c|}{ Dry Hyperbaric Hyperoxia } & \multicolumn{2}{|c|}{ Immersed Hyperbaric Hyperoxia } \\
\hline & & 15 minutes & 5 hours & 15 minutes & 5 hours \\
\hline \multicolumn{6}{|l|}{ Cardiac diameters } \\
\hline $\mathrm{LA}(\mathrm{mm})$ & $36.3+/-3.8$ & $29.5+/-3.0 *$ & $28.6+/-4.2 *$ & $34.6+/-2.5^{£}$ & $34+/-2.4^{£}$ \\
\hline LVEDD (mm) & $53.5+/-3.5$ & $50.9+/-3.5 *$ & $50.6+/-3.7 *$ & $52.9+/-2.5^{£}$ & $52.4+/-2$ \\
\hline LVESD (mm) & $34.2+/-2.6$ & $34.3+/-3.6$ & $34.6+/-2.6$ & $34.3+/-2.9$ & $34.9+/-2$ \\
\hline$\% \mathrm{FS}(\%)$ & $36+/-3$ & $32+/-5 *$ & $31+/-3 *$ & $35+/-4^{£}$ & $33+/-3$ \\
\hline \multicolumn{6}{|l|}{ LV afterload indices } \\
\hline Total arterial compliance $(\mathrm{ml} / \mathrm{mmHg})$ & $1.97+/-0.38$ & $1.74+/-0.57$ & $1.49+/-0.30 *$ & $1.81+/-0.52$ & $1.52+/-0.34 *$ \\
\hline LV meridional wall stress (dynes $/ \mathrm{cm}^{2}$ ) & $69+/-11$ & $81+/-13 *$ & $84+/-16 *$ & $69+/-16^{£}$ & $69+/-7^{£}$ \\
\hline
\end{tabular}

* $p<0.05$ versus reference, $\S p<0.05$ versus $15 \mathrm{~min}$ of the same environment, ${ }^{£} \mathrm{p}<0.05$ versus dry at the same time point 
Table 4 : Left ventricular filling profile recorded during immersed session

Sea level Immersed Hyperbaric Hyperoxia 15 minutes 5 hours

E max velocity $(\mathrm{cm} / \mathrm{s})$

$73+/-11$

$69+/-6$

$65+/-13$

A max velocity $(\mathrm{cm} / \mathrm{s})$

$44+/-11 \quad 38.0+/-8$

$41+/-11$

E/A

$1.75+/-0.50$

$1.66+/-0.44$

$1.51+/-0.35$

Contribution of atrial contraction

to LV filling (\%)

$23+/-6$

$19+/-5$

$21+/-5$

PHT $(\mathrm{cm} / \mathrm{s})$

$57.7+/-9.9$

$70+/-15$

$75+/-28$

IVRT (ms)

90. $+/-7$

$93+/-10$

$100+/-10$ 
Figure 1 : Peak inspiratory and expiratory pressures recorded at different depths in diver using the closed-circuit SCUBA Oxymixgers 97

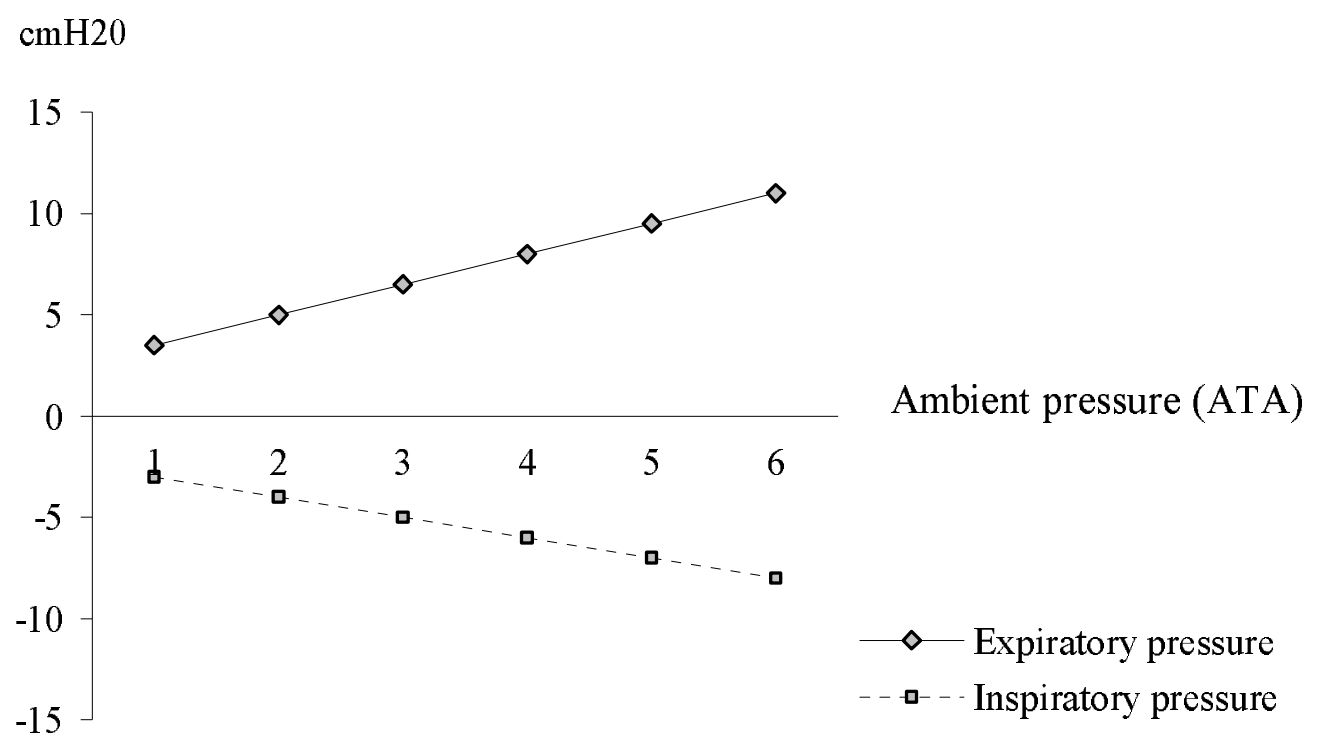


Figure 2 : Evolution of central temperature in the ten subjects, during the immersed hyperbaric hyperoxic exposure

* significant (compared with sea level - reference)

\% Echocardiography

Exercise 




